\title{
Research Article \\ Effects of Flavonoids on Rumen Fermentation Activity, Methane Production, and Microbial Population
}

\author{
Ehsan Oskoueian, ${ }^{1,2}$ Norhani Abdullah, ${ }^{1,3}$ and Armin Oskoueian ${ }^{1,4}$ \\ ${ }^{1}$ Institute of Tropical Agriculture, Universiti Putra Malaysia, 43400 Serdang, Selangor, Malaysia \\ ${ }^{2}$ Agriculture Biotechnology Research Institute of Iran (ABRII), East and North-East Branch, P.O. Box 91735/844, Mashhad, Iran \\ ${ }^{3}$ Department of Biochemistry, Faculty of Biotechnology and Biomolecular Sciences, Universiti Putra Malaysia, \\ 43400 Serdang, Selangor, Malaysia \\ ${ }^{4}$ Ferdowsi University of Mashhad, International Branch, P.O. Box 91779/4888, Mashhad, Iran \\ Correspondence should be addressed to Norhani Abdullah; norhani.biotech@gmail.com
}

Received 14 April 2013; Revised 12 August 2013; Accepted 26 August 2013

Academic Editor: Nico Boon

Copyright (C) 2013 Ehsan Oskoueian et al. This is an open access article distributed under the Creative Commons Attribution License, which permits unrestricted use, distribution, and reproduction in any medium, provided the original work is properly cited.

\begin{abstract}
This research was carried out to evaluate the effects of flavone, myricetin, naringin, catechin, rutin, quercetin, and kaempferol at the concentration of $4.5 \%$ of the substrate (dry matter basis) on the rumen microbial activity in vitro. Mixture of guinea grass and concentrate $(60: 40)$ was used as the substrate. The results showed that all the flavonoids except naringin and quercetin significantly $(P<0.05)$ decreased the dry matter degradability. The gas production significantly $(P<0.05)$ decreased by flavone, myricetin, and kaempferol, whereas naringin, rutin, and quercetin significantly $(P<0.05)$ increased the gas production. The flavonoids suppressed methane production significantly $(P<0.05)$. The total VFA concentration significantly $(P<0.05)$ decreased in the presence of flavone, myricetin, and kaempferol. All flavonoids except naringin and quercetin significantly $(P<0.05)$ reduced the carboxymethyl cellulase, filter paperase, xylanase, and $\beta$-glucosidase activities, purine content, and the efficiency of microbial protein synthesis. Flavone, myricetin, catechin, rutin, and kaempferol significantly $(P<0.05)$ reduced the population of rumen microbes. Total populations of protozoa and methanogens were significantly $(P<0.05)$ suppressed by naringin and quercetin. The results of this research demonstrated that naringin and quercetin at the concentration of $4.5 \%$ of the substrate (dry matter basis) were potential metabolites to suppress methane production without any negative effects on rumen microbial fermentation.
\end{abstract}

\section{Introduction}

The highly diverse methanogenic community present in the rumen have been implicated in global warming, and attempts to manipulate rumen microbial fermentation towards reducing the methane production through application of feed additives remain a high priority [1]. For the past decades, several additives, such as ionophores and probiotics, have been introduced to the ruminant production industry [2]. The ionophores such as monensin, lasalocid, and laidlomycin significantly suppressed the methane production in ruminants [3]. However, concerns including antibiotic resistance and detectable residual levels of these compounds in animal products limit the utilization of these additives [4]. In the case of probiotics, the commonly used microorganisms for ruminants are yeast and Aspergillus oryzae. These microbes increase butyrate or propionate acids concentration, reduce protozoa numbers, and promote acetogenesis which resulted in lower methane production [5]. However, the use of probiotics to inhibit methane production in ruminants is limited due to the cost; hence, appropriate strategies are required for the large-scale production of probiotics with economical operating expenditure [6].

Recently, natural plant products which are often inexpensive and environmentally safe have been introduced in methane mitigation strategies. They could be superior feed additives to replace the ionophores and probiotics for controlling methanogenesis [7]. These compounds are not only able to suppress the methane production but also possess broad range of favorable effects on animal health. For instance, 
their major affects on gastrointestinal tract include improvement in digestibility, feed efficiency, protection of dietary proteins from rumen microbial degradation, maintaining the gut microflora balance, gastric or liver damage prevention, reduction in gastrointestinal spasms, diarrhea, constipation, bloat, acidosis, and controlling gut pathogens [8].

Furthermore, their main effects on respiratory and cardiovascular system in animals include emollient, antitussive, expectorant, hypotensive, cardioprotective, and vascularstabilizing properties [9]. They also possess antihyperlipidemic, hypocholesterolaemic, and diuretic properties. These compounds are capable of reducing fear, depression, and anxiety and showed to have antipyretic and analgaesic effects. The enhancements in immune function, reproductive organs, fertility, wool growth, and ectoparasites elimination have also been reported $[8,10]$.

Among plant secondary metabolites, flavonoids have gained importance because of their wide range of biological activities and in particular antimicrobial properties. Flavonoids are classified under polyphenolic compounds as they possess $\mathrm{A}$ and $\mathrm{C}$ rings of benzo-1-pyran-4-quinone and a $\mathrm{B}$ ring [11]. These natural compounds are believed to have direct effects against methanogens [12] and to be an alternative agent to suppress methane production and improve animal health and productivity.

The plant flavonoids are generally present in the glycosides form with the aglycone linked to a variable sugar moiety by a $\beta$-glycosidic bond, mainly in position 3 of the $\mathrm{C}$ ring $[11,13]$. The presence of sugar moiety reduces the bioactivity of flavonoid; thus, the removal of sugar moiety not only enhances the functional properties of flavonoid but also improves the bioavailability in the gastrointestinal tract. A recent study by Berger et al. [13] showed that rumen microbes enhanced the bioavailability of flavonoid rutin (quercetin3-O-rutinoside) by degradation of glycosidic linkage. This degradation resulted in libration of quercetin. Further, the quercetin and its methylated (isorhamnetin, tamarixetin) and dehydroxylated (kaempferol) derivatives were detected in plasma of nonlactating cows. Similarly, a recent study by Gohlke et al. [14] compared the bioavailability of quercetin in the aglycone and glucorhamnoside forms through duodenal administration in German Holstein cows. Their results showed higher intestinal bioavailability of quercetin in the aglycone form as compared to the glucorhamnoside form.

Plant extracts rich in flavonoids have gained importance in improving animal production. Tedesco et al. [15] reported the increase in milk yield and lactation performance in dairy cows upon $25 \mathrm{~d}$ administration of sylimarin $(10 \mathrm{~g} / \mathrm{d})$ which mainly consist of flavonolignans. Likewise, Balcells et al. [16] showed that plant extract containing flavonoids at the concentration of $300 \mathrm{mg} / \mathrm{kg}$ DM was able to decrease the incidence of acidosis and enhance the animal growth performance in cattle receiving high-concentrate diet. This phenomenon was attributed to the decrease in the titers of Streptococcus bovis and Selenomonas ruminantium and increase in the numbers of lactate-consuming microorganisms such as Megasphaera elsdenii.

Currently, various flavonoids-rich feed additives to suppress the methane production are available in the market.
However, these products mainly contain plant crude extracts, and it is rather difficult to correlate the response of rumen microbes to the flavonoids. The presence of other components such as glycosides, phenolics, terpenoids, alkaloids, essential oils, and organic acids in the plant extracts may influence the results. Furthermore, the information on the effect of flavonoids in the pure form on rumen microbial activity is still lacking $[13,14,16]$.

Taking all these considerations into account, this research hypothesised that the flavonoids depending on their types are capable of modulating the rumen fermentation activity in varying degrees. Hence, in order to test this hypothesis, in vitro gas production technique was applied to evaluate the effect of different types of flavonoids in the pure forms on rumen microbial fermentation, methane production, enzyme activity, microbial protein synthesis, and microbial population.

\section{Material and Methods}

2.1. Flavonoids. The flavonoids (purity $\geq 98 \%$ ) consisting of flavone, myricetin, naringin, catechin, rutin, quercetin, and kaempferol were purchased from Sigma (St. Louis, MO, USA).

2.2. In Vitro Rumen Fermentation. The in vitro gas production technique has been considered as an acceptable method to evaluate the effect of phytochemicals on rumen microbial fermentation [17]. Two male cows, fitted with rumen fistula, were maintained on a diet consisting of $60 \%$ guinea grass and $40 \%$ commercial cow pellet (FFM Berhad, Malaysia) which contained corn grain, palm kernel cake, soybean meal, rice bran, palm kernel oil, limestone, salt, and vitaminmineral premix. The proximate chemical composition of the diet (g/kg DM) was 146 crude protein, 485 neutral detergent fiber, 36.9 crude lipid, 83.9 ash, and metabolizable energy $10.04 \mathrm{MJ} / \mathrm{Kg}$ DM. The diet was offered twice daily and animals had free access to drinking water. The animals were used as rumen fluid donors.

Two hundred milligram of feed consisting of dry guinea grass and concentrate at $60: 40$ ratio was used as the substrate for the in vitro fermentation. The incubation medium was prepared as described by Menke and Steingass [18], and $30 \mathrm{~mL}$ was dispensed anaerobically into each $100 \mathrm{~mL}$ syringe. Each flavonoid was dissolved in ethanol and the concentration of $4.5 \%(\mathrm{w} / \mathrm{w})$ of the substrate on dry matter basis $(9 \mathrm{mg})$ was included in each syringe. The final ethanol concentration of each syringe was $0.5 \%(\mathrm{v} / \mathrm{v})$. The control consisted of substrate with $0.5 \%(\mathrm{v} / \mathrm{v})$ ethanol. The syringes were incubated at $39^{\circ} \mathrm{C}$ for $24 \mathrm{~h}$. In vitro gas production (GP) was measured at $2,4,8,12$, and $24 \mathrm{~h}$. A total of nine syringes for each treatment were used. The content of three syringes were used for dry matter degradability (DMD), $\mathrm{pH}$, and fermentation parameters and another three for microbial protein synthesis, and the remaining three syringes were used for quantification of rumen microbial population and enzyme activity assays. This experiment was performed in three separate runs. The volatile fatty acids (VFAs), which include acetic, isobutyric, butyric, propionic, valeric, isovaleric, and caproic acids, were 
determined by gas chromatography (Agilent 6890 A) which was equipped with a capillary column packed with $10 \%$ (w/v) PEG 600 on Shimalate TPA 60/80 [19]. After $24 \mathrm{~h}$ incubation, methane production was measured by injecting $1 \mathrm{~mL}$ of the headspace gas from each of the syringes into a gas chromatograph (Agilent 5890 Series Gas Chromatograph, Wilmington, DE, USA) equipped with FID detector. Separation was achieved using an HP-Plot Q column $(30 \mathrm{~m}$ $\times 0.53 \mathrm{~mm} \times 40 \mathrm{~m}$ ) (Agilent Technologies, Wilmington, DE, USA) with nitrogen (99.9\% purity, Domnick-Hunter generator, Domnick-Hunter, Leicester, UK) as the carrier gas at the flow rate of $3.5 \mathrm{~mL} / \mathrm{min}$. An isothermal oven temperature of $50^{\circ} \mathrm{C}$ was used in the separation. Calibration was completed using standard methane prepared by Scotty Specialty Gases (Supelco, Bellefonte, PA, USA). The ammonia nitrogen content was determined by the Kjeldahl procedure [20]. Cumulative gas production data were fitted to the model of Ørskov and McDonald [21], and the values of $a$ (the gas production from the immediately soluble fraction), $b$ (the gas production from the insoluble fraction), $a+b$ (potential extent of gas production), and $c$ (gas production rate constant for the insoluble fraction $b$ ) were estimated using the nonlinear regression (NLIN) procedure of SAS [22]. All animal management and sampling procedures were approved by the Universiti Putra Malaysia Animal Care and Use Committee [23].

2.3. Rumen Microbial Enzyme Activity. In order to extract the microbial enzyme, the whole content of each syringe after $24 \mathrm{~h}$ incubation was transferred to a $50 \mathrm{~mL}$ centrifuge tube and mixed with $5 \mathrm{~mL}$ carbon tetrachloride and lysozyme solution $(0.4 \mathrm{~g} / 100 \mathrm{~mL}$ phosphate buffer, $0.1 \mathrm{M}$, and $\mathrm{pH} 6.8)$ and further incubated at $40^{\circ} \mathrm{C}$ for $3 \mathrm{~h}$ followed by $60 \mathrm{~s}$ sonication at $4^{\circ} \mathrm{C}$ using a sonicator (Vibra Cell sonicator, Sonics and Materials, Danbury, CT, USA). The sonicated samples were centrifuged at $24,000 \times \mathrm{g}$ for $20 \mathrm{~min}$ at $4^{\circ} \mathrm{C}$, and the clear supernatant was used for the estimation of enzyme activities [24].

The enzymes studied were filter paperase (FPase), carboxymethylcellulase (CMCase), $\beta$-glucosidase, and xylanase as described by Saad et al. [25]. Filterpaper, carboxymethylcellulose, $\rho$-nitrophenyl- $\beta$-D-glucopyranoside, and xylan were used as substrates to determine the FPase, CMCase, $\beta$-glucosidase, and xylanase activities, respectively. Filterpaperase, CMCase, and xylanase activities were determined by measuring the production of reducing sugar using dinitrosalicylic acid (DNSA) [26]. $\beta$-glucosidase activity was measured by the amount of $\rho$-nitrophenol released from the $\rho$-nitrophenyl- $\beta$-D-glucopyranoside (PNPG). Each enzyme assay was carried out in triplicate. Protein content of supernatant was determined according to Bradford [27]. The specific activity of each enzyme (CMCase, FPase, xylanase, or $\beta$-glucosidase) was expressed as $\mu \mathrm{mol}$ of product (glucose/xylose/4-nitrophenol) released $/ \mathrm{min} / \mathrm{mg}$ protein under the assay conditions.

2.4. Rumen Microbial Protein Synthesis. Microbial protein synthesis was determined according to the method described by Makkar and Becker [28] using purines as a marker. After $24 \mathrm{~h}$ fermentation, the content of each syringe was centrifuged at $20,000 \times \mathrm{g}$ for $30 \mathrm{~min}$ and the supernatant was discarded. The pellet was washed with distilled water followed by centrifugation $(20,000 \times \mathrm{g}$ for $30 \mathrm{~min})$. The pellet, consisting of undigested substrate and microbial mass, was lyophilized. Aliquot of $2.5 \mathrm{~mL}$ of perchloric acid $(0.6 \mathrm{M})$ was added to $100 \mathrm{mg}$ of each lyophilized sample and the mixture was incubated in a water bath at $90-95^{\circ} \mathrm{C}$ for $1 \mathrm{~h}$. The $\mathrm{pH}$ of solution was adjusted between 6.6 and 6.9 using concentrated $\mathrm{KOH}(8 \mathrm{M})$ and the solution was centrifuged at $3,000 \times \mathrm{g}$ for $15 \mathrm{~min}$ to remove the precipitate. Then, the supernatant was filtered through $0.45 \mu \mathrm{m}$ filter. The adenine and guanine contents were quantitatively measured in the supernatant by high-performance liquid chromatography (HPLC) equipped with a reverse phase C18 LiChrospher 100, $250 \times 4 \mathrm{~mm}$ I.D and $5 \mu \mathrm{m}$ pore size column (Agilent Technologies, Waldbronn, Germany). Absorbance was monitored at $254 \mathrm{~nm}$ and guanine and adenine peaks appeared at about 8.3 and $11.1 \mathrm{~min}$, respectively. Allopurinol was used as the internal standard which appeared at about $16.6 \mathrm{~min}$. The efficiency of microbial protein synthesis (EMPS) was calculated by dividing the total purines by total gas or total volatile fatty acids (VFAs).

2.5. Rumen Microbial Population Analysis. At the end of the incubation, $1 \mathrm{~mL}$ of rumen fluid containing digesta was used for DNA extraction using QIAamp DNA Stool Mini Kit (QIAGEN). The primer sets used in this study are shown in Table 1. The 16S rRNA of bacteria and 18S rRNA of protozoa, and fungi were amplified by PCR using primers for general bacteria, general fungi, total protozoa, Ruminococcus flavefaciens, Fibrobacter succinogenes, Ruminococcus albus, and total methanogens. The PCR products were cloned in pCR2.1-TOPO TA cloning vector (Invitrogen, Carlsbad, CA, USA) and transformed into chemically competent $E$. coli TOP10 cells (Invitrogen). The plasmids were extracted and sequenced using capillary electrophoresis on an Applied Biosystems 3730xl DNA Analyzer (Applied Biosystems, Foster City, CA, USA). The sequences were checked for chimeric rDNA using Bellerophon [29] and were compared to those available in the GenBank using the Basic Local Alignment Search Tool [30]. The plasmid carrying the sequence that was $\geq 99 \%$ similar to the previously published sequence of the target microorganism was used for real-time PCR amplification and standard curve construction. The concentration and purity of the plasmid for each group of microorganisms was determined using Nanodrop (NanoDrop Technologies, Wilmington, DE, USA), and the number of copies was determined using the following formula [31]

$$
\frac{\text { Amount of DNA }(\mu \mathrm{g} / \mathrm{mL}) \times 6.022 \times 10^{23}}{\text { Length }(\mathrm{bp}) \times 10^{9} \times 650} \text {. }
$$

Real-time PCR assays were conducted on a BioRad CFX 96 real-time PCR thermocycler (Bio-Rad, Hercules, USA) using iQ SYBR Green Supermix (Bio-Rad Laboratories, Inc., Hercules, CA, USA). Data from the real-time PCR reactions 
TABLE 1: PCR primer sets used in this study*.

\begin{tabular}{lcccc}
\hline Microorganism & Forward & Reverse & Amplicon size (bp) & Reference \\
\hline General bacteria & cggcaacgagcgcaaccc & ccattgtagcacgtgtgtagcc & 130 & {$[45]$} \\
General fungi & gaggaagtaaaagtcgtaacaaggtttc & caaattcacaaagggtaggatgatt & 120 & {$[45]$} \\
Total protozoa & gctttcgwtggtagtgtatt & cttgcctcyaatcgtwct & 223 & 343 \\
Total methanogens & cgwagggaagctgttaagt & taccgtcgtccactcctt & 175 & $132]$ \\
Ruminococcus albus & ccctaaaagcagtcttagttcg & cctccttgcggttagaaca & {$[47]$} \\
Ruminococcus flavefaciens & cgaacggagataatttgagtttacttagg & cggtctctgtatgttatgaggtattacc & {$[48]$} \\
Fibrobacter succinogenes & gttcggaattactgggcgtaaa & cgcctgccctgaactatc & {$[45]$} & 121 \\
\hline
\end{tabular}

* Primer sequence $\left(5^{\prime} \rightarrow 3^{\prime}\right)$.

TABLE 2: Effects of flavonoids on dry matter degradability, total gas, methane and gas production parameters.

\begin{tabular}{|c|c|c|c|c|c|c|c|c|c|}
\hline \multirow{2}{*}{ Items } & \multicolumn{8}{|c|}{ Treatments } & \multirow{2}{*}{ SEM } \\
\hline & Ctrl & $\mathrm{F}$ & M & $\mathrm{N}$ & $\mathrm{C}$ & $\mathrm{R}$ & Q & $\mathrm{K}$ & \\
\hline Dry matter degradability (\%) & $87.9^{\mathrm{a}}$ & $81.3^{\mathrm{b}}$ & $82.1^{\mathrm{b}}$ & $86.1^{\mathrm{a}}$ & $82.0^{\mathrm{b}}$ & $81.5^{\mathrm{b}}$ & $85.6^{\mathrm{a}}$ & $83.2^{\mathrm{b}}$ & 1.2 \\
\hline Total gas $(\mathrm{mL} / 24 \mathrm{~h})$ & $36.1^{\mathrm{c}}$ & $28.1^{\mathrm{d}}$ & $30.6^{\mathrm{d}}$ & $47.8^{\mathrm{a}}$ & $36.9^{c}$ & $40.9^{\mathrm{b}}$ & $43.0^{\mathrm{b}}$ & $34.8^{\mathrm{c}}$ & 0.94 \\
\hline $\mathrm{CH}_{4}(\mathrm{~mL} / \mathrm{g} \mathrm{DM})$ & $8.6^{\mathrm{a}}$ & $5.7^{\mathrm{cd}}$ & $4.9^{\mathrm{d}}$ & $6.3^{c}$ & $7.9^{\mathrm{ab}}$ & $7.2^{\mathrm{b}}$ & $6.2^{\mathrm{c}}$ & $5.3^{\mathrm{d}}$ & 0.29 \\
\hline$(a+b)(\mathrm{mL})$ & $41.1^{\mathrm{c}}$ & $32.4^{\mathrm{d}}$ & $34.2^{\mathrm{d}}$ & $56.7^{\mathrm{a}}$ & $43.7^{\mathrm{c}}$ & $48.7^{\mathrm{b}}$ & $55.4^{\mathrm{a}}$ & $40.3^{\mathrm{c}}$ & 1.63 \\
\hline$c\left(\mathrm{~h}^{-1}\right)$ & $0.08^{\mathrm{ab}}$ & $0.09^{\mathrm{a}}$ & $0.09^{\mathrm{a}}$ & $0.05^{\mathrm{b}}$ & $0.09^{\mathrm{a}}$ & $0.06^{\mathrm{b}}$ & $0.06^{\mathrm{b}}$ & $0.09^{\mathrm{a}}$ & 0.007 \\
\hline
\end{tabular}

Ctrl: control F: flavone, M: myricetin, N: naringin, C: catechin, R: rutin, Q: quercetin, and K: kaempferol. $a, b, c$, and $a+b$ are calculated from the exponential equation $p=a+b\left(1-e^{c t}\right)$.

$(a+b)=$ potential extent of gas production, $c=$ gas production rate constant for the insoluble fraction $(b)$.

Means within the same row with different superscripts are significantly different $(P<0.05)$.

were analyzed using CFX manager software version 3 (BioRad Laboratories). All real-time PCR amplifications were performed in triplicate.

2.6. Statistical Analyses. The data were analysed using the general linear models (GLM) procedure of SAS [22] in a completely randomized design (CRD), and means were compared with Duncan's multiple range test. Means were considered significantly different at $P<0.05$.

\section{Results and Discussion}

The effects of flavonoids at the concentration of $4.5 \%(\mathrm{w} / \mathrm{w})$ of the substrate on rumen dry matter (DM) degradability, total gas, and methane gas production kinetics are shown in Table 2. The in vitro DM degradability of control group was $87.9 \%$ and all flavonoids except naringin and quercetin reduced this value significantly $(P<0.05)$ to the range of 81.3 to $83.2 \%$. The total gas production of the control was $36.1 \mathrm{~mL}$ (Table 2$)$ and this value was significantly $(P<0.05)$ decreased to 28.1 and $30.6 \mathrm{~mL}$ when the flavone and myricetin were added, respectively. On the other hand, naringin, rutin, and quercetin increased the gas production significantly $(P<$ 0.05 ) to $47.8,40.9$, and $43.0 \mathrm{~mL}$, respectively.

The control treatment showed the production of $8.6 \mathrm{~mL} / \mathrm{g}$ DM methane and inclusion of flavone, myricetin, naringin, rutin, quercetin, and kaempferol significantly $(P<0.05)$ decreased the values to $5.7,4.9,6.3,7.2,6.2$, and $5.3 \mathrm{~mL} / \mathrm{g} \mathrm{DM}$, respectively. The inhibitory activities of flavonoids used in this experiment towards methanogenesis can be categorized in descending order as follows: myricetin $\geq$ kaempferol $\geq$ flavone $>$ quercetin $\geq$ naringin $>$ rutin $\geq$ catechin. The suppression of methane production observed in this study was in accordance with the result of Tavendale et al. [32] who demonstrated the potential of flavonol to decrease methane production in Methanobrevibacter ruminantium culture. Besides, Patra et al. [24] have also indicated that plant extract containing flavonoids could decrease the methane production. Generally, the decrease in the dry matter degradability, total gas, and methane production upon addition of flavonoids could be attributed to the antimicrobial action of flavonoids [33, 34].

The potential extent of gas production indicated by the $a+b$ values is in accordance with the results in gas production during fermentation. As observed, these values were significantly $(P<0.05)$ higher in treatments with naringin, rutin, and quercetin and lower in treatments with flavone and myricetin (Table 2). The gas production rate constants for the insoluble fraction $(b)$ are presented as $c$ values in Table 2. The $c$ value for the control was $0.08 \%$, and addition of naringin, rutin, and quercetin reduced this significantly $(P<0.05)$. The increase in the gas production of $a+b$ led to the decrease in the $c$ value as previously described by Ørskov and McDonald [21].

The addition of flavonoids did not affect the $\mathrm{pH}$ and ammonia nitrogen significantly as shown in Table 3 . The total VFA concentration of control group was $47.3 \mathrm{mM}$, but the addition of flavone, myricetin, and kaempferol significantly $(P<0.05)$ reduced the total VFA concentration to $41.3,39.1$, and $42.3 \mathrm{mM}$, respectively. The decrease in total VFAs values implied the antimicrobial action of flavonoids. However, in 
TABLE 3: Effects of flavonoids on $\mathrm{pH}$, ammonia, and volatile fatty acids.

\begin{tabular}{|c|c|c|c|c|c|c|c|c|c|}
\hline \multirow{2}{*}{ Items } & \multicolumn{8}{|c|}{ Treatments } & \multirow{2}{*}{ SEM } \\
\hline & Ctrl & $\mathrm{F}$ & M & $\mathrm{N}$ & $\mathrm{C}$ & $\mathrm{R}$ & $\mathrm{Q}$ & $\mathrm{K}$ & \\
\hline $\mathrm{pH}$ & 6.8 & 6.8 & 6.8 & 6.8 & 6.8 & 6.8 & 6.8 & 6.8 & 0.01 \\
\hline Ammonia N (mg/100 mL) & 36.5 & 37.6 & 37.5 & 36.2 & 36.2 & 36.2 & 37.4 & 35.6 & 0.57 \\
\hline Total VFA (mM) & $47.3^{\mathrm{a}}$ & $41.3^{\mathrm{b}}$ & $39.1^{\mathrm{c}}$ & $47.0^{\mathrm{a}}$ & $47.1^{\mathrm{a}}$ & $46.7^{\mathrm{a}}$ & $46.5^{\mathrm{a}}$ & $42.3^{\mathrm{b}}$ & 0.58 \\
\hline Acetic acid (molar \%) & $58.0^{\mathrm{a}}$ & $52.6^{\mathrm{b}}$ & $53.3^{\mathrm{b}}$ & $60.2^{\mathrm{a}}$ & $58.7^{\mathrm{a}}$ & $60.1^{\mathrm{a}}$ & $60.5^{\mathrm{a}}$ & $53.6^{\mathrm{b}}$ & 1.71 \\
\hline Propionic acid (molar \%) & $19.5^{\mathrm{a}}$ & $16.2^{\mathrm{b}}$ & $16.9^{\mathrm{b}}$ & $17.8^{\mathrm{ab}}$ & $19.0^{\mathrm{a}}$ & $17.5^{\mathrm{ab}}$ & $17.6^{\mathrm{ab}}$ & $16.6^{\mathrm{b}}$ & 0.75 \\
\hline Butyric acid (molar \%) & $13.8^{\mathrm{b}}$ & $17.4^{\mathrm{a}}$ & $18.1^{\mathrm{a}}$ & $15.1^{\mathrm{b}}$ & $15.5^{\mathrm{b}}$ & $15.3^{\mathrm{b}}$ & $15.1^{\mathrm{b}}$ & $17.7^{\mathrm{a}}$ & 0.66 \\
\hline C2: C3 ratio $^{\mathrm{b}}$ & $3.0^{\mathrm{b}}$ & $3.2^{\mathrm{ab}}$ & $3.1^{\mathrm{ab}}$ & $3.4^{\mathrm{a}}$ & $3.1^{\mathrm{ab}}$ & $3.4^{\mathrm{a}}$ & $3.4^{\mathrm{a}}$ & $3.2^{\mathrm{ab}}$ & 0.20 \\
\hline
\end{tabular}

Ctrl: control F: flavone, M: myricetin, N: naringin, C: catechin, R: rutin, Q: quercetin, and K: kaempferol.

$\mathrm{C} 2$ : C3: acetate : propionate ratio.

Means within the same row with different superscripts are significantly different $(P<0.05)$.

TABLE 4: Effects of flavonoids on the specific activity of enzymes in buffered rumen fluid.

\begin{tabular}{|c|c|c|c|c|c|c|c|c|c|}
\hline \multirow{2}{*}{ Enzymes $(\mu \mathrm{mol} / \mathrm{min} / \mathrm{mg}$ protein $)$} & \multicolumn{8}{|c|}{ Treatments } & \multirow{2}{*}{ S.E.M } \\
\hline & Ctrl & $\mathrm{F}$ & M & $\mathrm{N}$ & $\mathrm{C}$ & $\mathrm{R}$ & Q & $\mathrm{K}$ & \\
\hline CMCase & $0.45^{\mathrm{a}}$ & $0.31^{\mathrm{bc}}$ & $0.28^{\mathrm{c}}$ & $0.43^{\mathrm{a}}$ & $0.35^{\mathrm{b}}$ & $0.34^{\mathrm{b}}$ & $0.41^{\mathrm{ab}}$ & $0.29^{\mathrm{c}}$ & 0.05 \\
\hline FPase & $0.29^{\mathrm{a}}$ & $0.15^{\mathrm{c}}$ & $0.14^{\mathrm{c}}$ & $0.28^{\mathrm{a}}$ & $0.22^{\mathrm{b}}$ & $0.23^{\mathrm{b}}$ & $0.27^{\mathrm{a}}$ & $0.14^{c}$ & 0.03 \\
\hline Xylanase & $0.82^{\mathrm{a}}$ & $0.47^{\mathrm{b}}$ & $0.41^{\mathrm{b}}$ & $0.76^{\mathrm{a}}$ & $0.52^{\mathrm{b}}$ & $0.53^{\mathrm{b}}$ & $0.75^{\mathrm{a}}$ & $0.42^{\mathrm{b}}$ & 0.11 \\
\hline$\beta$-Glucosidase & $0.14^{\mathrm{a}}$ & $0.07^{\mathrm{b}}$ & $0.08^{\mathrm{b}}$ & $0.15^{\mathrm{a}}$ & $0.09^{\mathrm{b}}$ & $0.09^{\mathrm{b}}$ & $0.13^{\mathrm{a}}$ & $0.08^{\mathrm{b}}$ & 0.006 \\
\hline
\end{tabular}

Ctrl: control F: flavone, M: myricetin, N: naringin, C: catechin, R: rutin, Q: quercetin, and K: kaempferol.

Means within the same row with different superscripts are significantly different $(P<0.05)$.

treatments with naringin, catechin, rutin, and quercetin, the total VFAs concentrations were comparable to the control. In the case of catechin and rutin, in spite of the decrease in DM degradability, the VFA concentration was not significantly suppressed, which indicated the possible utilization of these flavonoids as fermentable substrates. It has been reported by McSweeney et al. [35] that rutin, naringin, and quercitrin are readily degraded in the rumen and their derivatives are utilized by rumen microbes. Smith et al. [36] reported the microbial degradation of flavonoids in the rumen which occurred through cleavage of their $\mathrm{C}$ rings resulting in phenolic acids and nonaromatic fermentation products. Thus, these byproducts could play a role as an alternative carbon source for rumen microbial activities.

The molar percentage of acetic acid and propionic acid were significantly $(P<0.05)$ reduced in treatments with flavone, myricetin, and kaempferol, with concomitant increase in butyric acid when compared to the control. On the other hand, molar percentages of acetic, propionic, and butyric acids in treatments with naringin, catechin, rutin, and quercetin were comparable to the control. In line with this result, Lowry and Kennedy [37] and McSweeney and Mackie [38] have reported the increase in concentration of acetic and butyric acids upon fermentation of rutin, naringin, and quercetin by rumen microbes. The increase in acetic to propionic (C2: $\mathrm{C} 3)$ ratio reflects an increase in acetic acid and slight decrease in propionic acid concentrations.

It is interesting to note that CMCase, FPase, xylanase, and $\beta$-glucosidase activities in treatments with naringin and quercetin were comparable to the control (Table 4 ), whereas other flavonoids reduced these activities significantly $(P<$
0.05). The results showed that the specific activity of xylanase in buffered rumen fluid was higher than that of the CMCase and FPase. Xylanase is a measure of hemicellulase activity, while CMCase and FPase indicate cellulolytic activity. The levels of enzyme activities were in accordance with the percentage of DM degradability.

The decrease in CMCase, FPase, xylanase, and $\beta$ glucosidase specific activities of fermenting rumen fluid in the presence of flavone, myricetin, and kaempferol could be related to the higher antimicrobial action of these compounds or their derivatives produced during fermentation. The enzyme activities of rumen microbes treated with naringin and quercetin are in accordance with the results in DM degradability and end products of fermentation. The effects of naringin and quercetin on rumen fermentation in this research are similar to that of methanolic extract of garlic reported by Kamra et al. [39]. The garlic methanolic extract reduced the methane production without impairing the ruminal enzyme activity and in vitro DM degradability.

According to Lowry and Kennedy [37], quercetin, a phenolic aglycone, although insoluble in water, can be rapidly degraded by rumen microbes and enhance the rumen microbial activity. Lowry and Kennedy have also observed an inhibition of rumen microbial activity in the presence of catechin, despite of its close structural relationship to quercetin. These observations are comparable with the results obtained in this experiment showing the positive effects of quercetin and negative effects of catechin on rumen microbial activities.

The adenine, guanine, and purine content of control group were $2.1,1.4$, and $3.6 \mu \mathrm{moL}$, respectively (Table 5). The 
TABLE 5: Effects of flavonoids on purine content and efficiency of rumen microbial protein synthesis.

\begin{tabular}{|c|c|c|c|c|c|c|c|c|c|}
\hline & \multicolumn{8}{|c|}{ Treatments } & \multirow{2}{*}{ SEM } \\
\hline & Ctrl & $\mathrm{F}$ & $\mathrm{M}$ & $\mathrm{N}$ & $\mathrm{C}$ & $\mathrm{R}$ & Q & $\mathrm{K}$ & \\
\hline Adenine $(\mu \mathrm{mol})$ & $2.1^{\mathrm{a}}$ & $1.3^{\mathrm{c}}$ & $1.3^{\mathrm{c}}$ & $2.2^{\mathrm{a}}$ & $1.4^{\mathrm{bc}}$ & $1.5^{\mathrm{bc}}$ & $2.0^{\mathrm{a}}$ & $1.3^{\mathrm{c}}$ & 0.07 \\
\hline Guanine $(\mu \mathrm{mol})$ & $1.4^{\mathrm{a}}$ & $0.9^{\mathrm{b}}$ & $1.0^{\mathrm{b}}$ & $1.4^{\mathrm{a}}$ & $1.0^{\mathrm{b}}$ & $1.0^{\mathrm{b}}$ & $1.3^{\mathrm{a}}$ & $0.9^{\mathrm{b}}$ & 0.07 \\
\hline Purines $(\mu \mathrm{mol})$ & $3.6^{\mathrm{a}}$ & $2.2^{\mathrm{c}}$ & $2.3^{\mathrm{c}}$ & $3.7^{\mathrm{a}}$ & $2.4^{\mathrm{bc}}$ & $2.6^{\mathrm{bc}}$ & $3.4^{\mathrm{a}}$ & $2.2^{\mathrm{c}}$ & 0.14 \\
\hline \multicolumn{10}{|c|}{ Efficiency of microbial protein synthesis (EMPS) } \\
\hline$\mu \mathrm{mol}$ purine $/ \mathrm{mL}$ gas & $0.10^{\mathrm{a}}$ & $0.07^{\mathrm{b}}$ & $0.07^{\mathrm{b}}$ & $0.08^{\mathrm{ab}}$ & $0.06^{\mathrm{b}}$ & $0.06^{\mathrm{b}}$ & $0.08^{\mathrm{ab}}$ & $0.06^{\mathrm{b}}$ & 0.01 \\
\hline$\mu \mathrm{mol}$ purine/mmol total VFA & $0.08^{\mathrm{a}}$ & $0.05^{\mathrm{b}}$ & $0.06^{\mathrm{b}}$ & $0.08^{\mathrm{a}}$ & $0.05^{\mathrm{b}}$ & $0.05^{\mathrm{b}}$ & $0.08^{\mathrm{a}}$ & $0.05^{\mathrm{b}}$ & 0.01 \\
\hline
\end{tabular}

Ctrl: control F: flavone, M: myricetin, N: naringin, C: catechin, R: rutin, Q: quercetin, and K: kaempferol.

Means within the same row with different superscripts are significantly different $(P<0.05)$.

TABLE 6: The slope of the standard curve and real-time PCR amplification efficiency.

\begin{tabular}{lcc}
\hline Microorganisms & Slope & Efficiency \\
\hline General bacteria & -3.32 & 100.1 \\
General fungi & -3.43 & 95.6 \\
Total protozoa & -3.32 & 102.5 \\
Total methanogens & -3.33 & 101.1 \\
Fibrobacter succinogenes & -3.31 & 102.8 \\
Ruminococcus albus & -3.30 & 100.9 \\
Ruminococcus flavefaciens & -3.33 & 99.8 \\
\hline
\end{tabular}

TABLE 7: Effect of flavonoids on different rumen microbial population.

\begin{tabular}{|c|c|c|c|c|c|c|c|c|}
\hline \multirow{2}{*}{ Items } & \multicolumn{7}{|c|}{ Treatments } & \multirow{2}{*}{ SEM } \\
\hline & $\mathrm{F}$ & M & $\mathrm{N}$ & $\mathrm{C}$ & $\mathrm{R}$ & Q & $\mathrm{K}$ & \\
\hline \multicolumn{9}{|c|}{ General bacteria $\times 10^{14}$ copies $/ \mathrm{mL}$ of rumen fluid } \\
\hline $6.5^{\mathrm{a}}$ & $3.7^{\mathrm{b}}$ & $3.5^{\mathrm{b}}$ & $5.4^{\mathrm{a}}$ & $5.3^{\mathrm{a}}$ & $4.9^{\mathrm{ab}}$ & $5.3^{\mathrm{a}}$ & $3.4^{\mathrm{b}}$ & 1.22 \\
\hline \multicolumn{9}{|c|}{ General fungi $\times 10^{5}$ copies $/ \mathrm{mL}$ of rumen fluid } \\
\hline $3.7^{\mathrm{a}}$ & $2.1^{\mathrm{b}}$ & $2.1^{\mathrm{b}}$ & $3.2^{\mathrm{a}}$ & $2.6^{\mathrm{ab}}$ & $2.9^{\mathrm{ab}}$ & $3.4^{\mathrm{a}}$ & $2.3^{\mathrm{b}}$ & 0.36 \\
\hline \multicolumn{9}{|c|}{ Total protozoa $\times 10^{6}$ copies $/ \mathrm{mL}$ of rumen fluid } \\
\hline $3.8^{\mathrm{a}}$ & $1.1^{\mathrm{c}}$ & $1.9^{\mathrm{b}}$ & $1.9^{\mathrm{b}}$ & $2.1^{\mathrm{b}}$ & $2.6^{\mathrm{ab}}$ & $2.3^{\mathrm{b}}$ & $1.5^{\mathrm{bc}}$ & 0.31 \\
\hline \multicolumn{9}{|c|}{ Total methanogens $\times 10^{7}$ copies $/ \mathrm{mL}$ of rumen fluid } \\
\hline $1.7^{\mathrm{a}}$ & $1.0^{\mathrm{b}}$ & $0.7^{\mathrm{b}}$ & $0.6^{\mathrm{b}}$ & $1.1^{\mathrm{ab}}$ & $1.3^{\mathrm{a}}$ & $0.9^{\mathrm{b}}$ & $1.1^{\mathrm{ab}}$ & 0.22 \\
\hline \multicolumn{9}{|c|}{ Fibrobacter succinogenes $\times 10^{6}$ copies $/ \mathrm{mL}$ of rumen fluid } \\
\hline $3.5^{\mathrm{a}}$ & $1.4^{\mathrm{c}}$ & $1.6^{\mathrm{bc}}$ & $3.2^{\mathrm{a}}$ & $2.7^{\mathrm{ab}}$ & $2.5^{\mathrm{b}}$ & $3.1^{\mathrm{a}}$ & $1.4^{\mathrm{c}}$ & 0.26 \\
\hline \multicolumn{9}{|c|}{ Ruminococcus albus $\times 10^{5}$ copies $/ \mathrm{mL}$ of rumen fluid } \\
\hline $2.4^{\mathrm{a}}$ & $1.5^{\mathrm{bc}}$ & $1.8^{\mathrm{b}}$ & $2.3^{\mathrm{a}}$ & $2.0^{\mathrm{ab}}$ & $1.8^{\mathrm{b}}$ & $2.4^{\mathrm{a}}$ & $1.5^{\mathrm{bc}}$ & 0.18 \\
\hline \multicolumn{9}{|c|}{ Ruminococcus flavefaciens $\times 10^{5}$ copies $/ \mathrm{mL}$ of rumen fluid } \\
\hline $5.1^{\mathrm{a}}$ & $3.7^{\mathrm{b}}$ & $3.2^{\mathrm{bc}}$ & $5.2^{\mathrm{a}}$ & $4.2^{\mathrm{b}}$ & $4.3^{\mathrm{ab}}$ & $4.9^{\mathrm{a}}$ & $3.1^{\mathrm{c}}$ & 0.28 \\
\hline
\end{tabular}

Ctrl: control F: flavone, M: myricetin, N: naringin, C: catechin, R: rutin, Q: quercetin, and K: kaempferol.

Means within the same row with different superscripts are significantly different $(P<0.05)$

addition of naringin and quercetin did not affect these values significantly; whereas the adenine, guanine, and purine content were significantly $(P<0.05)$ decreased upon addition of flavone, myricetin, catechin, rutin, and kaempferol. The estimated EMPS values of control were $0.10 \mu \mathrm{moL}$ purine $/ \mathrm{mL}$ gas and $0.08 \mu \mathrm{moL}$ purine $/ \mathrm{mmoL}$ total VFA and these values did not show significant difference when compared to both naringin and quercetin treated samples. However, flavone, myricetin, catechin, rutin, and kaempferol significantly $(P<$ 0.05) decreased the EMPS when compared to the control. Similarly, these parameters supported the results obtained in DM degradability, total gas production, total VFAs, and enzyme activities of naringin- and quercetin-treated samples.

Broudiscou et al. [40] reported that the A. millefolium, A. chamissonis, and L. angustifolia leaves extracts which contained flavonoids increased without changes or decreased the EMPS, respectively. The variations in the results may relate to the type and concentration of the flavonoids present in the plant extract. In case of high concentration of flavonoids, the EMPS may decrease as observed in this study. Flavonoids used in this study were capable of modulating the EMPS; however, the appropriate levels to increase the EMPS need to be investigated.

The precision of rumen microbial quantification using real-time PCR is revealed by the slope of standard curve and the PCR amplification efficiency values (Table 6). The slope and amplification efficiency obtained in this research ranged from -3.30 to -3.43 and from 95.6 to 102.8 , respectively. Zhang and Fang [41] recommended the reliable standard curve in practice to have slope between -3.0 and -3.9 corresponding to PCR efficiencies of $80-115 \%$. Thus, all the values for the slope and PCR amplification efficiency obtained in this study were in the acceptable range.

The quantity of the rumen microbes affected by flavonoids is presented in Table 7. As observed with other parameters, the addition of naringin and quercetin had no significant effects on the population of general bacteria, general fungi, Fibrobacter succinogenes, Ruminococcus albus, and Ruminococcus flavefaciens when compared to the control. While these flavonoids significantly $(P<0.05)$ suppressed the population of total protozoa and total methanogens. The addition of flavone, myricetin, catechin, rutin, and kaempferol significantly $(P<0.05)$ reduced the population of almost all of the rumen microorganisms. The reduction of methane producing microorganisms is reflective of the decrease in methane production as shown in Table 2. It has been suggested that the flavonoids directly [1] or through new derivatives produced upon biotransformation or degradation [42] affect the rumen microbial activity. The effects of naringin and quercetin towards rumen microbes 
are desirable and they should be considered as alternative compounds to manipulate the rumen microbes towards maintaining the cellulolytic bacteria with lower protozoa and methanogens population.

The flavonoids generally act against microorganisms through inhibition of cytoplasmic membrane function, inhibition of bacterial cell wall synthesis, or inhibition of nucleic acid synthesis [34]. In addition, the antimicrobial potential of flavonoids is dependent on the number and the position of hydroxyl groups and presence of aliphatic and glycosyl groups in their structures. For instance, the active flavonoids against Methicillin-resistant Staphylococcus aureus are hydroxyl group at position 5 of flavones and flavanones [43]. Moreover, Mirzoeva et al. [44] reported the antibacterial action of quercetin and naringin against $E$. coli through disruption of proton motive force and inhibition of bacterial motility. To date, no much information is available on the mechanism of action of flavonoids against rumen microbes. The results obtained in this study indicated that flavone, myricetin, and kaempferol markedly reduced rumen microbial fermentation activity while catechin and rutin showed minimal effect. In contrast, naringin and quercetin maintained rumen microbial fermentation activity, with significant reduction in methane production.

\section{Conclusions}

The naringin and quercetin at the concentration of $4.5 \%$ (w/w) of the substrate (on dry matter basis) suppressed methane production and decreased rumen protozoa and methanogens population. The DM degradability and other fermentation parameters were not affected by these flavanoids. Future studies on feeding ruminant with plants rich in quercetin and naringin may allow the development of a natural and acceptable technique to manipulate rumen fermentation towards lower methane production.

\section{Conflict of Interests}

The authors declare no financial or proprietary interests in any materials or methods reported in this paper.

\section{Authors' Contribution}

All authors are involved in the work presented in this paper.

\section{Acknowledgment}

The facilities provided by the Institute of Bioscience and the Institute of Tropical Agriculture, Universiti Putra Malaysia, are gratefully acknowledged.

\section{References}

[1] A. K. Patra and J. Saxena, "A new perspective on the use of plant secondary metabolites to inhibit methanogenesis in the rumen," Phytochemistry, vol. 71, no. 11-12, pp. 1198-1222, 2010.
[2] I. Karakurt, G. Aydin, and K. Aydiner, "Sources and mitigation of methane emissions by sectors: a critical review," Renewable Energy, vol. 39, no. 1, pp. 40-48, 2012.

[3] C. H. Ponce, D. R. Smith, M. E. Branine, M. E. Hubbert, and M. L. Galyean, "Effects of type of ionophore and carrier on in vitro ruminal dry matter disappearance, gas production, and fermentation end products of a concentrate substrate," Animal Feed Science and Technology, vol. 171, no. 2-4, pp. 223-229, 2012.

[4] D. J. Nisbet, T. R. Callaway, T. S. Edrington, R. C. Anderson, and N. Krueger, "Effects of the dicarboxylic acids malate and fumarate on E. coli O157:H7 and Salmonella enterica typhimurium populations in pure culture and in mixed ruminal microorganism fermentations," Current Microbiology, vol. 58, no. 5, pp. 488-492, 2009.

[5] M. F. Iqbal, Y. Cheng, W. Zhu, and B. Zeshan, "Mitigation of ruminant methane production: current strategies, constraints and future options," World Journal of Microbiology and Biotechnology, vol. 24, no. 12, pp. 2747-2755, 2008.

[6] N. J. Nusbaum, "Dairy livestock methane remediation and global warming," Journal of Community Health, vol. 35, no. 5, pp. 500-502, 2010.

[7] D. N. Kamra, M. Pawar, and B. Singh, "Effect of plant secondary metabolites on rumen methanogens and methane emissions by ruminants," in Dietary Phytochemicals and Microbes, A. K. Patra, Ed., pp. 351-370, Springer, Amsterdam, The Netherlands, 2012.

[8] Z. Durmic and D. Blache, "Bioactive plants and plant products: effects on animal function, health and welfare," Animal Feed Science and Technology, vol. 176, no. 1-4, pp. 150-162, 2012.

[9] L. J. McGaw and J. N. Eloff, "Ethnoveterinary use of southern African plants and scientific evaluation of their medicinal properties," Journal of Ethnopharmacology, vol. 119, no. 3, pp. 559-574, 2008.

[10] S. Rochfort, A. J. Parker, and F. R. Dunshea, "Plant bioactives for ruminant health and productivity," Phytochemistry, vol. 69, no. 2, pp. 299-322, 2008.

[11] A. Crozier, I. B. Jaganath, and M. N. Clifford, "Phenols, polyphenols and Tannins: an overview," in Plant Secondary Metabolites, A. Crozier, M. N. Clifford, and H. Ashihara, Eds., pp. 1-24, Blackwell Publishing, Oxford, UK, 2007.

[12] R. Bodas, N. Prieto, R. Garcia-Gonzalez, S. Andres, F. J. Giraldez, and S. Lopez, "Manipulation of rumen fermentation and methane production with plant secondary metabolites," Animal Feed Science and Technology, vol. 176, no. 1-4, pp. 7893, 2012.

[13] L. M. Berger, S. Wein, R. Blank, C. C. Metges, and S. Wolffram, "Bioavailability of the flavonol quercetin in cows after intraruminal application of quercetin aglycone and rutin," Journal of Dairy Science, vol. 95, no. 9, pp. 5047-5055, 2012.

[14] A. Gohlke, C. J. Ingelmann, G. Nurnberg, A. Starke, S. Wolffram, and C. C. Metges, "Bioavailability of quercetin from its aglycone and its glucorhamnoside rutin in lactating dairy cows after intraduodenal administration," Journal of Dairy Science, vol. 96, no. 4, pp. 2303-2313, 2013.

[15] D. Tedesco, A. Tava, S. Galletti et al., "Effects of silymarin, a natural hepatoprotector, in periparturient dairy cows," Journal of Dairy Science, vol. 87, no. 7, pp. 2239-2247, 2004.

[16] J. Balcells, A. Aris, A. Serrano, A. R. Seradj, J. Crespo, and M. Devant, "Effects of an extract of plant flavonoids (Bioflavex) on rumen fermentation and performance in heifers fed highconcentrate diets," Journal of Animal Science, vol. 90, no. 13, pp. 4975-4984, 2012. 
[17] H. P. S. Makkar, "In vitro gas methods for evaluation of feeds containing phytochemicals," Animal Feed Science and Technology, vol. 123-124, pp. 291-302, 2005.

[18] K. H. Menke and H. Steingass, "Estimation of the energetic feed value obtained from chemical analysis and in vitro gas production using rumen fluid," Animal Research and Development, vol. 28, pp. 7-55, 1988.

[19] E. Oskoueian, N. Abdullah, W. Z. Saad, A. R. Omar, M. B. Puteh, and Y. W. Ho, "Anti-nutritional metabolites and effect of treated Jatropha curcas kernel meal on rumen fermentation in vitro," Journal of Animal and Veterinary Advances, vol. 10, no. 2, pp. 214-220, 2011.

[20] AOAC, Official Methods of Analysis, pp. 64-87, Association of Official Analytical Chemists, Washington, DC, USA, 15th edition, 1990.

[21] E. Ørskov and I. McDonald, “The estimation of protein degradability in the rumen from incubation measurements weighted according to rate of passage," The Journal of Agricultural Science, vol. 92, no. 2, pp. 499-503, 1979.

[22] SAS Institute Inc, SAS user's guide: Statistics. SAS for Windows, Release 9. 1. 3., SAS Institute Inc, Cary, NC, USA, 2003.

[23] Universiti Putra Malaysia Animal Care and Use Committee, Reference No. UPM/FPV/PS/3. 2. 1. 551/AUP-R32, Serdang, Selangor, Malaysia, 2008.

[24] A. K. Patra, D. N. Kamra, and N. Agarwal, "Effect of plant extracts on in vitro methanogenesis, enzyme activities and fermentation of feed in rumen liquor of buffalo," Animal Feed Science and Technology, vol. 128, no. 3-4, pp. 276-291, 2006.

[25] W. Z. Saad, N. Abdullah, A. R. Alimon, and Y. W. Ho, "Effects of phenolic monomers on the enzymes activities and volatile fatty acids production of Neocallimastix frontalis B9," Anaerobe, vol. 14, no. 2, pp. 118-122, 2008.

[26] G. L. Miller, "Use of dinitrosalicylic acid reagent for determination of reducing sugar," Analytical Chemistry, vol. 31, no. 3, pp. 426-428, 1959.

[27] M. M. Bradford, "A rapid and sensitive method for the quantitation of microgram quantities of protein utilizing the principle of protein dye binding," Analytical Biochemistry, vol. 72, no. 1-2, pp. 248-254, 1976.

[28] H. P. S. Makkar and K. Becker, "Purine quantification in digesta from ruminants by spectrophotometric and HPLC methods," British Journal of Nutrition, vol. 81, no. 2, pp. 107-112, 1999.

[29] T. Huber, G. Faulkner, and P. Hugenholtz, "Bellerophon: a program to detect chimeric sequences in multiple sequence alignments," Bioinformatics, vol. 20, no. 14, pp. 2317-2319, 2004.

[30] S. F. Altschul, T. L. Madden, A. A. Schäffer et al., "Gapped BLAST and PSI-BLAST: a new generation of protein database search programs," Nucleic Acids Research, vol. 25, no. 17, pp. 3389-3402, 1997.

[31] M. Li, G. B. Penner, E. Hernandez-Sanabria, M. Oba, and L. L. Guan, "Effects of sampling location and time, and host animal on assessment of bacterial diversity and fermentation parameters in the bovine rumen," Journal of Applied Microbiology, vol. 107, no. 6, pp. 1924-1934, 2009.

[32] M. H. Tavendale, L. P. Meagher, D. Pacheco, N. Walker, G. T. Attwood, and S. Sivakumaran, "Methane production from in vitro rumen incubations with Lotus pedunculatus and Medicago sativa, and effects of extractable condensed tannin fractions on methanogenesis," Animal Feed Science and Technology, vol. 123124, pp. 403-419, 2005.
[33] T. P. T. Cushnie and A. J. Lamb, "Recent advances in understanding the antibacterial properties of flavonoids," International Journal of Antimicrobial Agents, vol. 38, no. 2, pp. 99-107, 2011.

[34] T. P. T. Cushnie and A. J. Lamb, "Antimicrobial activity of flavonoids," International Journal of Antimicrobial Agents, vol. 26, no. 5, pp. 343-356, 2005.

[35] C. S. McSweeney, B. Palmer, D. M. McNeill, and D. O. Krause, "Microbial interactions with tannins: nutritional consequences for ruminants," Animal Feed Science and Technology, vol. 91, no. 1-2, pp. 83-93, 2001.

[36] A. H. Smith, E. Zoetendal, and R. I. Mackie, "Bacterial mechanisms to overcome inhibitory effects of dietary tannins," Microbial Ecology, vol. 50, no. 2, pp. 197-205, 2005.

[37] J. Lowry and P. Kennedy, "Fermentation of flavonols by rumen organisms," Proceeding of Australian Society of Animal Production, vol. 21, p. 366, 1996.

[38] C. McSweeney and R. Mackie, "Gastrointestinal detoxification and digestive disorders in ruminant animals," in Gastrointestinal Microbiology, R. Mackie and B. White, Eds., pp. 583-634, Springer, New York, NY, USA, 1997.

[39] D. N. Kamra, N. Agarwal, and L. C. Chaudhary, "Inhibition of ruminal methanogenesis by tropical plants containing secondary compounds," International Congress Series, vol. 1293, pp. 156-163, 2006.

[40] L. Broudiscou, Y. Papon, and A. F. Broudiscou, "Effects of dry plant extracts on feed degradation and the production of rumen microbial biomass in a dual outflow fermenter," Animal Feed Science and Technology, vol. 101, no. 1-4, pp. 183-189, 2002.

[41] T. Zhang and H. H. P. Fang, "Applications of real-time polymerase chain reaction for quantification of microorganisms in environmental samples," Applied Microbiology and Biotechnology, vol. 70, no. 3, pp. 281-289, 2006.

[42] A. L. Simons, M. Renouf, S. Hendrich, and P. A. Murphy, "Human gut microbial degradation of flavonoids: structurefunction relationships," Journal of Agricultural and Food Chemistry, vol. 53, no. 10, pp. 4258-4263, 2005.

[43] L. E. Alcaraz, S. E. Blanco, O. N. Puig, F. Tomas, and F. H. Ferretti, "Antibacterial activity of flavonoids against methicillinresistant Staphylococcus aureus strains," Journal of Theoretical Biology, vol. 205, no. 2, pp. 231-240, 2000.

[44] O. K. Mirzoeva, R. N. Grishanin, and P. C. Calder, "Antimicrobial action of propolis and some of its components: $t$ he effects on growth, membrane potential and motility of bacteria," Microbiological Research, vol. 152, no. 3, pp. 239-246, 1997.

[45] S. E. Denman and C. S. McSweeney, "Development of a realtime PCR assay for monitoring anaerobic fungal and cellulolytic bacterial populations within the rumen," FEMS Microbiology Ecology, vol. 58, no. 3, pp. 572-582, 2006.

[46] J. T. Sylvester, S. K. R. Karnati, Z. Yu, M. Morrison, and J. L. Firkins, "Development of an assay to quantify rumen ciliate protozoal biomass in cows using real-time PCR," Journal of Nutrition, vol. 134, no. 12, pp. 3378-3384, 2004.

[47] Y. Yu, C. Lee, J. Kim, and S. Hwang, "Group-specific primer and probe sets to detect methanogenic communities using quantitative real-time polymerase chain reaction," Biotechnology and Bioengineering, vol. 89, no. 6, pp. 670-679, 2005.

[48] S. Koike and Y. Kobayashi, "Development and use of competitive PCR assays for the rumen cellulolytic bacteria: Fibrobacter succinogenes, Ruminococcus albus and Ruminococcus flavefaciens," FEMS Microbiology Letters, vol. 204, no. 2, pp. 361-366, 2001. 

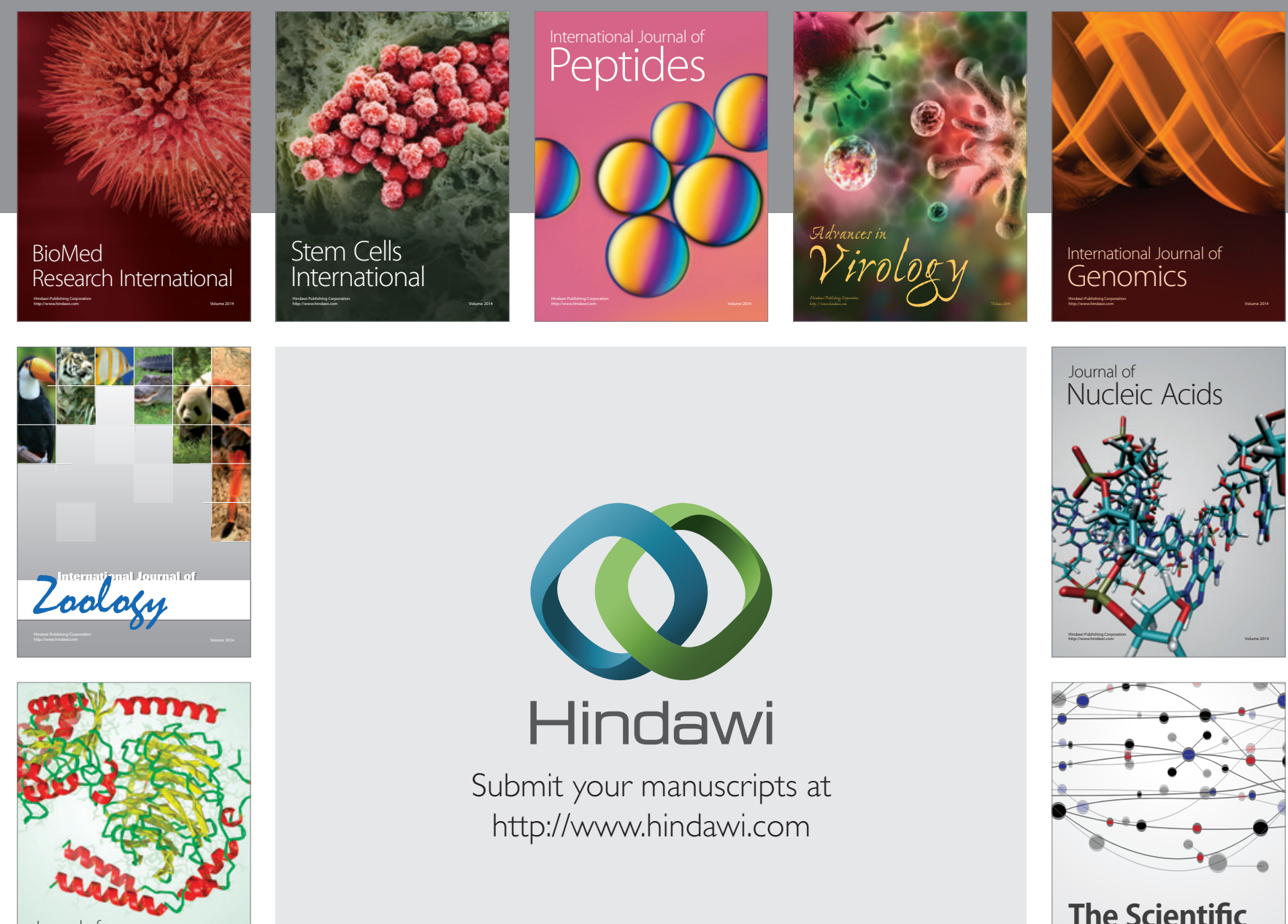

Submit your manuscripts at

http://www.hindawi.com

Journal of
Signal Transduction
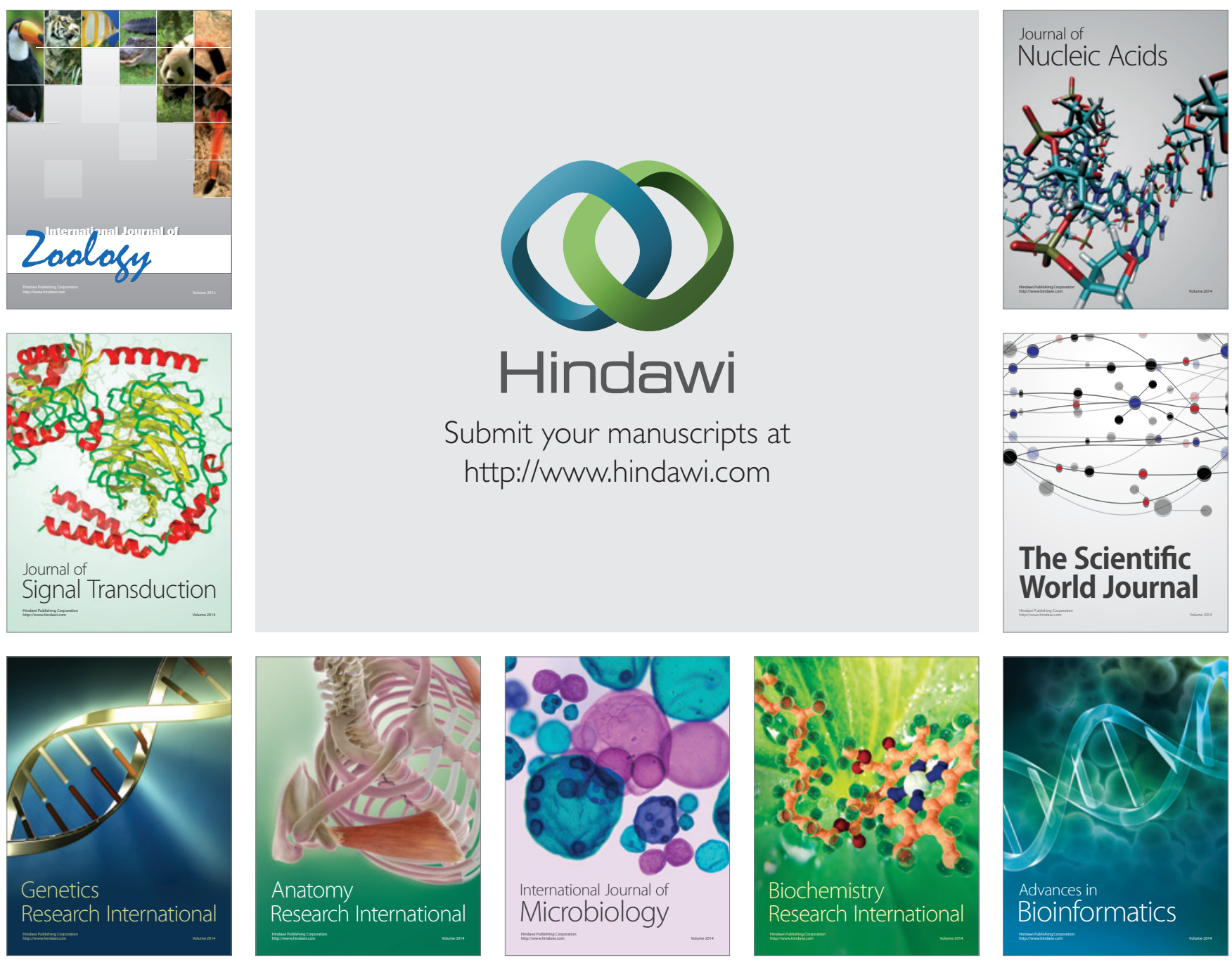

The Scientific World Journal
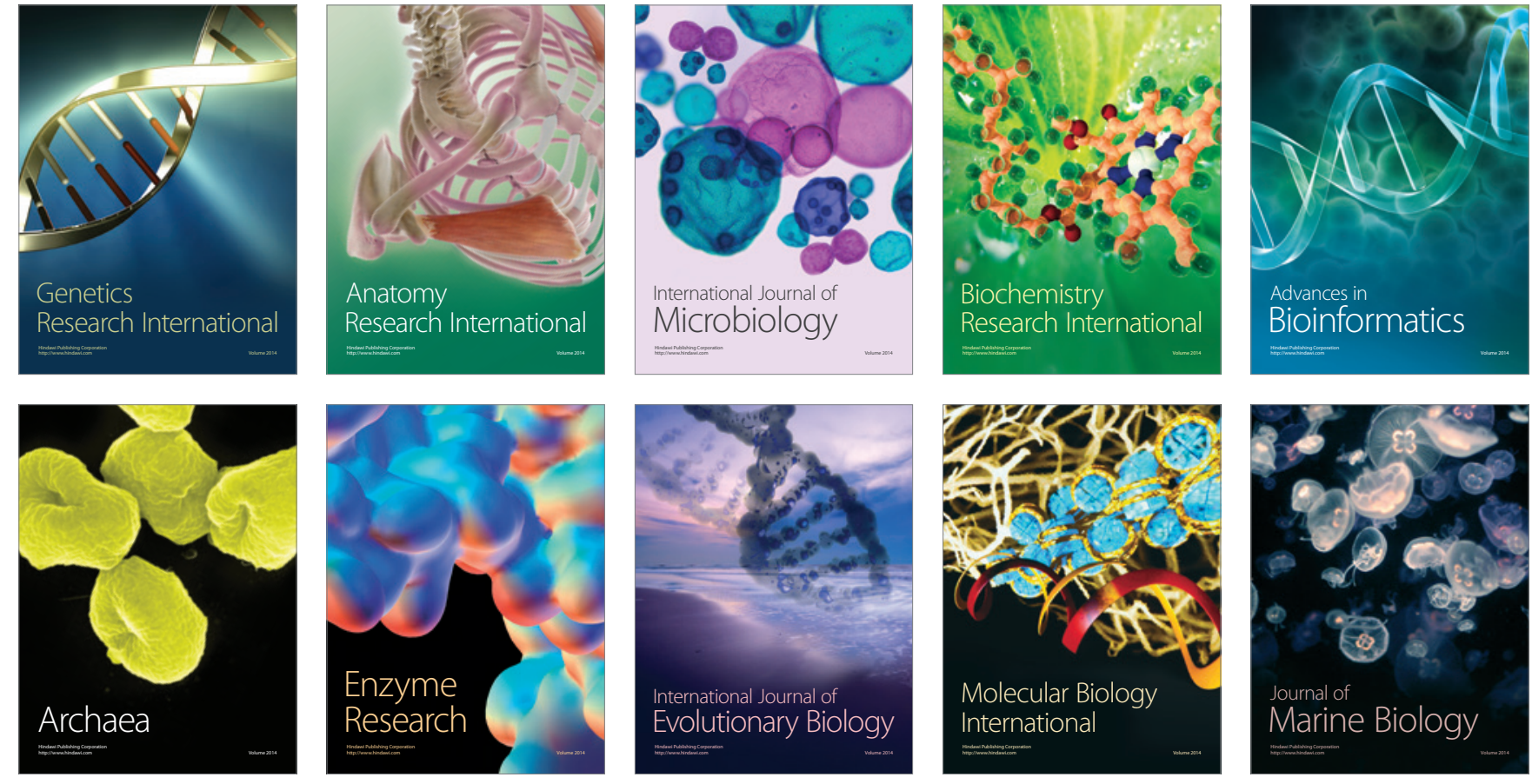